\title{
Comparative Residual Stress Analysis in Welded Joints Using Both Experimental and Numerical Techniques
}

\author{
Rajshekhar B. Aloor ${ }^{1 *}$, Ramakrishna H V², Nagabhushana Musalammagri ${ }^{3}$ \\ ${ }^{1}$ Department of Mechanical Engineering, B. N. M. Institute of Technology, Bengaluru, India \\ ${ }^{2}$ Department of Mechanical Engineering, Malnad College of Engineering, Hassan, India \\ ${ }^{3}$ Department of Mechanical Engineering, Kammavari Sangha Institute of Technology, Bengaluru, India \\ Email: *rajshekhar3396@gmail.com, hvr_2003@yahoo.com,naga_mnb@rediffmail.com
}

How to cite this paper: Aloor, R.B., Ramakrishna $\mathrm{H} \mathrm{V}$ and Musalammagri, $\mathrm{N}$. (2019) Comparative Residual Stress Analysis in Welded Joints Using Both Experimental and Numerical Techniques. Journal of Minerals and Materials Characterization and Engineering, 7, 150-156.

https://doi.org/10.4236/jmmce.2019.74011

Received: May 15, 2019

Accepted: June 17, 2019

Published: June 20, 2019

Copyright $\odot 2019$ by author(s) and Scientific Research Publishing Inc. This work is licensed under the Creative Commons Attribution International License (CC BY 4.0).

http://creativecommons.org/licenses/by/4.0/

\begin{abstract}
During cooling of the welds, the outer weld generally shrinks and the inner weld expands due to the differential cooling of outer and inner weld geometries. Due to this, tensile stresses can be observed in the inner weld and compressive stresses can be observed on the outer weld which forms the residual stress formation in the joints. Life and the load carrying capacity of the structures are very much influenced by the extent of residual stress in the joints. Estimation of this stress helps in estimating the safety of the structure subjected to various types of loads. Especially the tensile stresses are the possible causes of reduction in strength as well as for fatigue fracture failures. $\mathrm{X}$-ray diffraction technique (XRD), a non-destructive testing method, is used to find the residual stress in the present problem and the same problem is validated through finite element analysis. Comparison shows matching results between experimental and finite element analysis. The work is to show the efficiency of Finite element analysis as good alternative to the experimental techniques which are costly and need precise, costly equipment along with longer time for testing. XRD pattern was also represented to find the peaks in the XRD measurement.
\end{abstract}

\section{Keywords}

Residual Stress, XRD, Ansys, Temperature

\section{Introduction}

Welding is a common manufacturing process in the engineering industry. It gives sufficient strength for the engineering structures for the given loads. But it 
has certain drawbacks of voids, cracks, and brittleness due to improper cooling rates along with high weld deposits. This results in improper strength for the weld which is a critical parameter in the life and load carrying capacity under given loading conditions. Especially cooling rates have drastic effect on residual stress formation which may result finally in fatigue fractures. High residual stress is undesirable in the weldments as they are the potential sources for failure of the joints. Even the fatigue life is decided by the formation of residual stress in the joint. But it is very common in the industrial process to cool the weldments by rapid cooling with water quenching. So in the present work, the effect of water quenching on the residual stress formation is analysed using XRD and finite element analysis. XRD has the advantage of finding the macro and micro stress measurement abilities. The salient literatures available on the welded configurations are as follows.

T. Ninh Nguyen et al. [1] discussed weld stress development due to various types of weld geometries on residual stress formation. Along with this, they have also carried out fatigue estimation on the residual problems. They found that both residual stress and fatigue load cause fatigue fracture in the weld along with weakening of the strength of the structure.

Drazan Cozak et al. [2] carried out weld strength analysis under fatigue loading using experimentation along with finite element estimation. They have carried out three-dimensional analysis to find the fatigue strength for weldments under residual stress formation. The results were compared and found excellent matching of both the results.

Myung Hyun Kim [3] applied two methods to find the strength of the weld using hot spot and structural stress methods. But he observed large deviation of the results. Finally he applied finite element analysis to estimate the stress in the welds. He applied shell analysis method and the results were matching with results obtained through hot spot method.

R. Melicher [4] discussed residual stress estimations in circumferential welds. The effect of nonlinearity in the material conditions along with the structural change effect on the residual stresses was discussed. A transient analysis using ansys software was done to find the time effects on the residual stress formation in joint. The plastic effects on the stress generation were estimated through tangent modulus application in the calculations. Andrea Capriccioli [5] has discussed about residual stress formation with single and multi-pass welds. Thermal distribution in the welds was discussed with both the type of welds along with effect of material change was also discussed. Both Inconel and AISI316 were analysed by giving temperature dependent properties (Elastic modulus, thermal conductivity, specific heat etc.). The effect of convection, conduction and radiation were considered for final stress estimations. Nonlinear contact algorithms were used at the interface regions.

M.V. Dalvi et al. [6] discussed about the application of finite element analysis in solving nonlinear thermo-mechanical stress estimations in the welded joints 
under transient loading conditions, also discussed about merits of finite element analysis in solving the weld stress problems compared to the conventional time consuming theoretical process which are difficult to obtain solution at all the locations. So large literature is available on the welded joints indicating the importance of welds in the engineering industry and most of the literature is related to thermo-mechanical loads along with testing procedure involving Finite element methods.

\section{Methodology}

Mild Steel weld plates were prepared to the size of $100 \mathrm{~mm}$ by $50 \mathrm{~mm}$ size and jointed with $1 \mathrm{~mm}, 2 \mathrm{~mm}$ and $3 \mathrm{~mm}$ weld deposits. X-ray diffraction technique was applied to find the weld residual stress in the joint. The same weldments were analysed with finite element analysis to find the actual residual stress for the given thermal conditions. The results were compared. The weldment pictures were as follows.

Figure 1 shows prepared weld models of $1 \mathrm{~mm}, 2 \mathrm{~mm}$ and $3 \mathrm{~mm}$ thick weld using precise deposition techniques. The plates were prepared, by initial cleaning for rust and dust formation on the plates. After preparing the samples, the X-Ray diffraction technique was used to find the residual stress condition of the weld. The XRD process is as given follows.

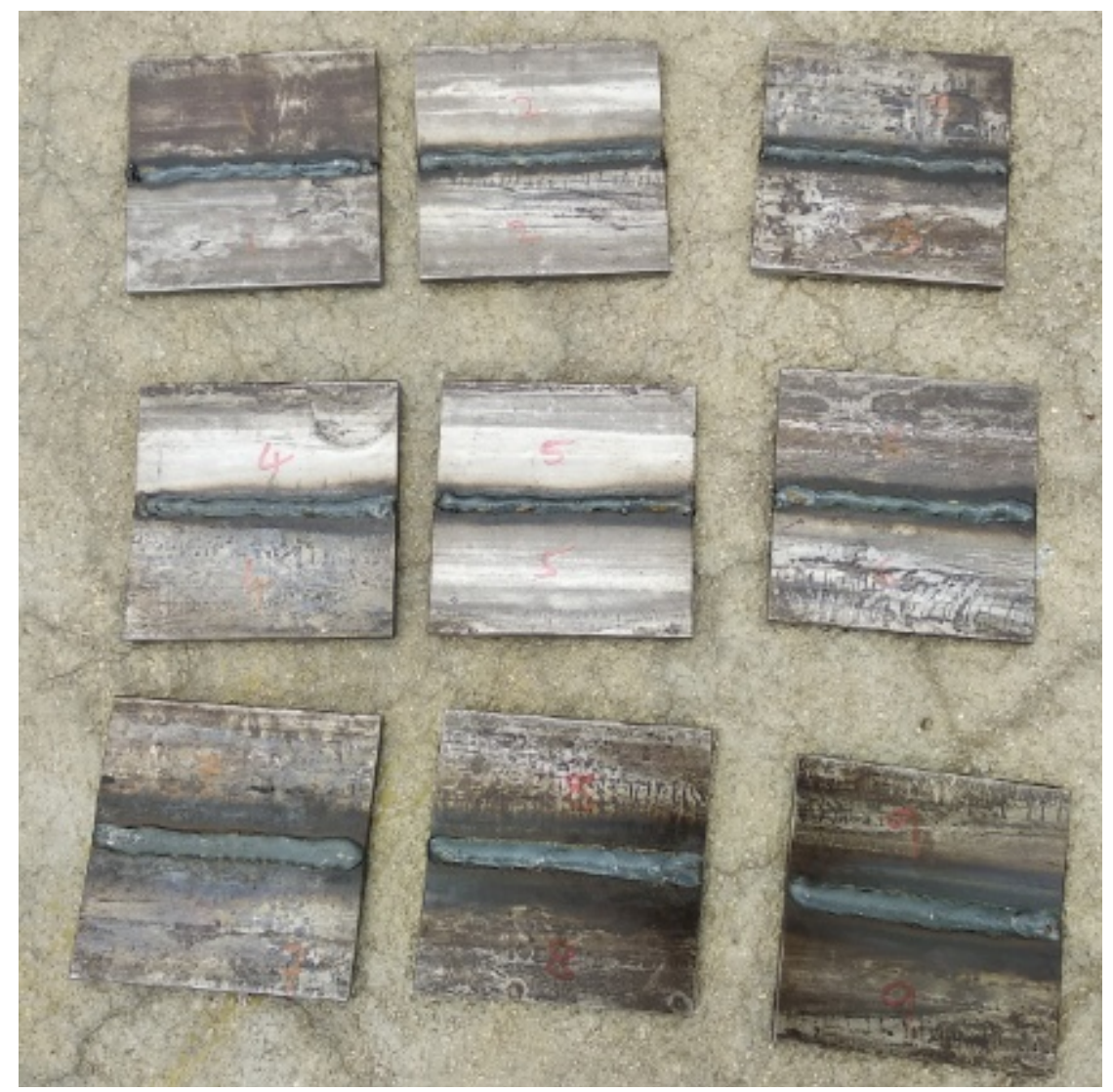

Figure 1. Weldments with $1 \mathrm{~mm}, 2 \mathrm{~mm}$ and $3 \mathrm{~mm}$ welds. 


\section{X-Ray Diffraction Technique and Residual Stress Measurements}

iXRD with MGR40P Stress measurement was used to apply XRD technique to find the residual stress in the members. The measurement is based on the distance between crystallographic planes (d-spacing). When the material is subjected to tension, the d-spacing will increase and reduces when it is in compression. Stresses were estimated based on the d-spacing. The X-ray tube is excited to an appropriate level before starting the actual measurements for about 15 minutes. The region of measurement is focused manually and parameters are set as per the requirements to obtain the optimum gain for better measurement of residual stress.

The required inputs like time of exposure, Beta \& Phi angles, number of averages etc. are supplied and the final measurement is done. The XRD pattern for the $1 \mathrm{~mm}$ weld configuration is as in Figure 2.

The d-spacing is estimated based on the XRD pattern as shown in Figure 2 represented for the given material which is essential for residual stress estimation.

The obtained results for residual stresses were as in Table 1.

Averaging the residual stress based on the sample size of three, the results are as in Table 2.

The results shown in Table 1 \& Table 2 clearly show reduction of residual stress with reference to multiple runs of the weld. This may be due to softening of the bottom weld (similar to heat treatment process) due to which certain residual stress will be relieved. So multiple runs are better compared to the single deposited weld which creates more residual stress in the joint.

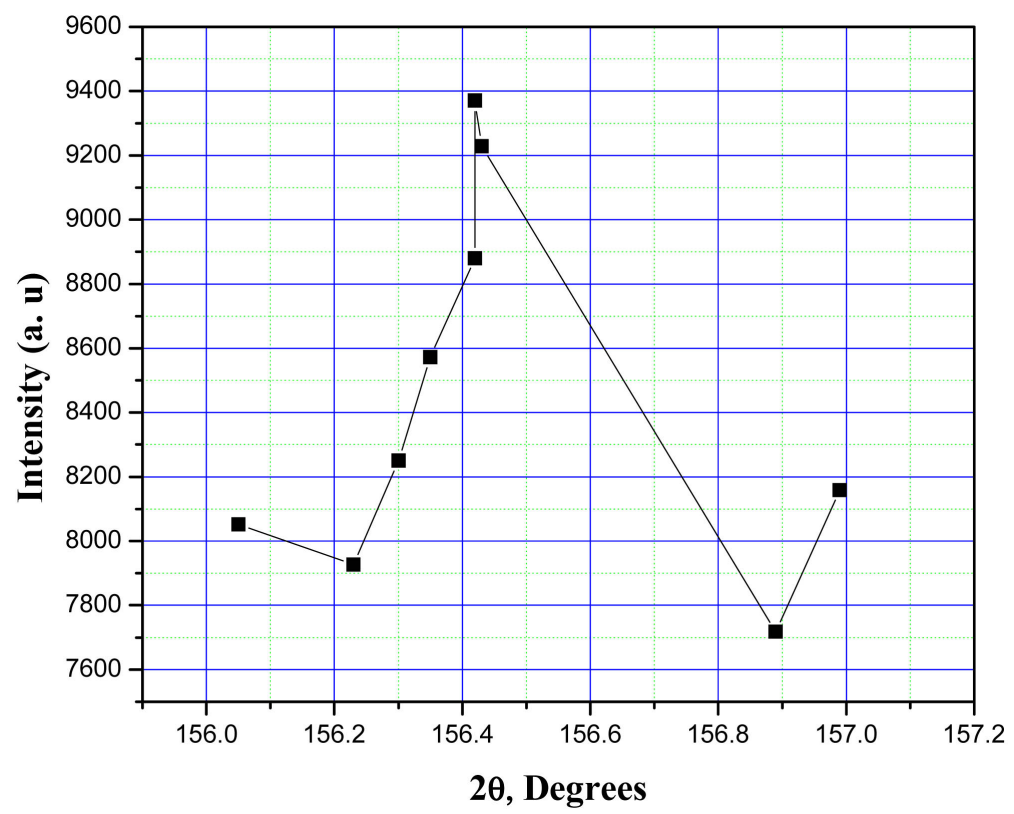

Figure 2. XRD pattern (origin software) of the $1 \mathrm{~mm}$ Weld simulated steel (211) Cr_Ka peak at $156.0^{\circ}$ using. 
Table 1. Residual stresses as per experimentation using XRD equipment.

\begin{tabular}{ccc}
\hline Sl. No & Job ID & Stress Value Measured in MPa \\
\hline 1 & 1 mm Welded-1 & $475.0 \pm 5.1$ \\
2 & 1 mm Welded-2 & $400.2 \pm 4.1$ \\
3 & 1 mm Welded-3 & $395.0 \pm 5.1$ \\
4 & 2 mm Welded-1 & $397.1 \pm 2.5$ \\
5 & 2 mm Welded-2 & $377.3 \pm 4.0$ \\
6 & 2 mm Welded-3 & $365.7 \pm 3.8$ \\
7 & 3 mm Welded-1 & $362.2 \pm 4.3$ \\
8 & 3 mm Welded-2 & $355.8 \pm 3.8$ \\
9 & $3 \mathrm{~mm}$ Welded-3 & $342.9 \pm 4.1$ \\
\hline
\end{tabular}

Table 2. Average residual stress in the Weldments using XRD equipment.

\begin{tabular}{ccc}
\hline Sl No & Size of Weld $(\mathrm{mm})$ & Average Residual Stress (Mpa) \\
\hline 1 & 1 & 398 \\
2 & 2 & 379 \\
3 & 3 & 353 \\
\hline
\end{tabular}

\section{Finite Element Analysis}

The geometry of the weld was prepared using ansys mixed approach and later meshed with hexahedra elements for accurate results. The analysis is carried out in the time domain to find the results. A direct process is used using Coupled field Solid5 element which has the capability to analyse both structural and thermal problems unlike a sequential process where two elements (Solid70 and Solid45) are required for stress measurement. The results are as in Figure 3.

Figure 3 shows weld stress in the $1 \mathrm{~mm}$ weld in the plates. Maximum stress is $398 \mathrm{Mpa}$ as shown in Figure 3. Graphical variation of stress was represented from bottom to the top of the plate using path operation command in the post processor of Ansys software.

Figure 4 shows minimum stresses at the bottom and maximum stress on the top region. Almost the graph shows a parabolic variation of stress from bottom to the top of the plate.

\section{Comparison of Experimental and Numerical Results}

Table 3 shows comparative estimations from X-Ray Diffraction technique and estimation from finite element solution. The results show very small deviation of numerical results from the experimental results. The percentage of error is very small and can be neglected. So finite element analysis has the advantage of finding the residual stress along with graphical plots for visual views of stress distribution which is not possible with experimental techniques. 


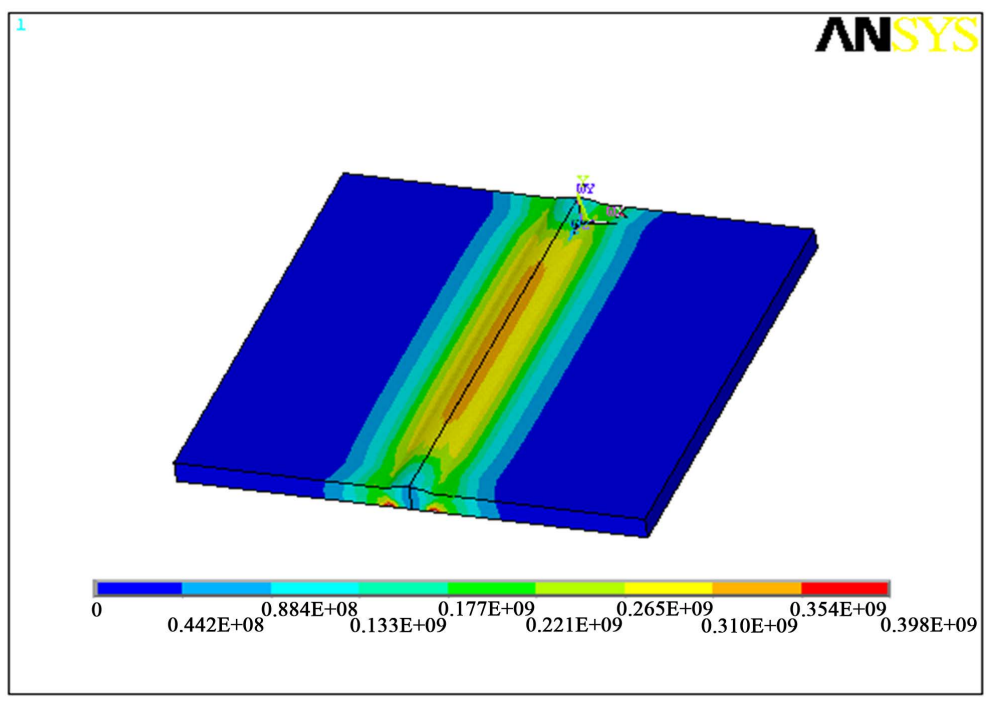

Figure 3. Residual Stress formation in the Welded configuration for $1 \mathrm{~mm}$ Weld.

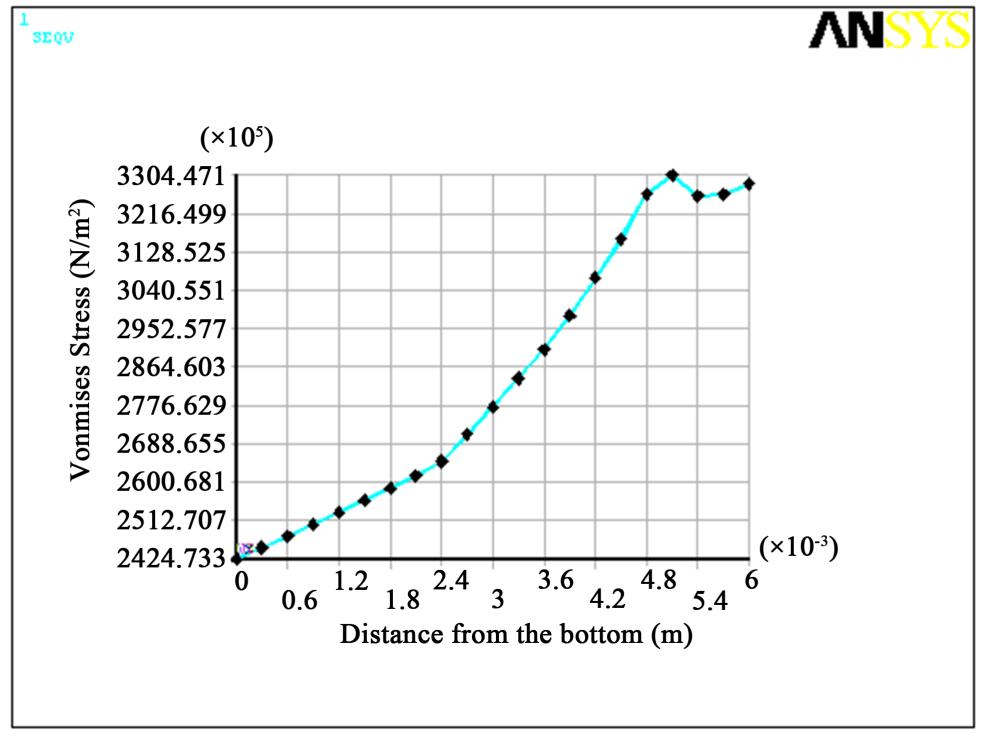

Figure 4. Stress variation from the bottom of the plate.

Table 3. Comparative results of finite element solution with experimental solution.

\begin{tabular}{cccc}
\hline Weld Configuration & Finite Element Solution & Experimental Solution & \% Error \\
\hline 1 mm Weld & 382 & 398 & 4 \\
2 mm Weld & 368 & 379 & 2.9 \\
3 mm Weld & 348 & 353 & 1.4 \\
\hline
\end{tabular}

\section{Conclusion}

Due to the complexity of weld stress estimation theoretically due to the nonlinear multiphase transient boundary conditions, experimental and numerical analysis was carried out to check the residual stress condition for quenched state of weld. The resulting stresses were high due to locking of the hot weld pool and 
the solidified top surface weld. The values were captured using X-ray diffraction technique and the same problem was analysed using finite element software ansys after inputting the nonlinear material properties in the transient domain. The results show excellent matching of results with very little error between the solutions, so Finite element analysis can be applied to find the stress condition of the weld for the given boundary conditions of solidification.

\section{Conflicts of Interest}

The authors declare no conflicts of interest regarding the publication of this paper.

\section{References}

[1] Ninh Nguyen, T. and Wahab, M.A. (1998) The Effect of Weld Geometry and Residual Stresses on the Fatigue of Welded Joint under Combine Loading. Journal of Material Processing Technology, 77, 201-208.

https://doi.org/10.1016/s0924-0136(97)00418-4

[2] Cozak, D. (1999) Finite Element Model of Welded Joint with Crack-Tip in the Heat Affected Zone. $5^{\text {th }}$ International Scientific Conference on Production Engineering, Opatija.

[3] Kim, M.H. (2006) A Comparative Study on the Fatigue Evaluation for Weldments under Out-Of Plane Bending Load Using Structural Stress and Hot Spot Stress. Key Engineering Materials, 326-328, 995-998. https://doi.org/10.4028/www.scientific.net/kem.326-328.995

[4] Melicher, R. (2007) Residual Stress Simulation of Circumferential Welded Joints. Applied and Computational Mechanics, 1, 541-548.

[5] Capriccioli, A. and Frosi, P. (2009) Multipurpose ANSYS FE Procedure for Welding Processes Simulation. G Model FUSION-4863, No. of Pages 8. https://doi.org/10.1016/j.fusengdes.2009.01.039

[6] Dalvi1, M.V., More, A.S.., Joshi, S.P. and Junnarkar, V.M. (2012) Determination of Failure Strength of Flat Plate Weld Joint Using Finite Element Analysis. International Journal of Scientific \& Engineering Research, 3. 